\title{
DESAFIOS DO EXERCÍCIO DA SOBERANIA NO CIBERESPAÇO
}

\author{
http://dx.doi.org/10.21527/2176-6622.2019.51.21-33
}

Recebido em: 20/4/2019

Aceito em: 3/6/2019

\section{Daniele Barbosa Mansur}

Graduanda em Direito pela Pontifícia Universidade Católica de Minas Gerais. danielemansur.dm@gmail.com

Bruno Anunciação Rocha

Mestrado em Teoria do Direito pela Pontifícia Universidade Católica de Minas Gerais. Pesquisador do CePPI/UFMG. bruno.a.rocha@gmail.com

\section{RESUMO}

O ciberespaço, com o seu modo de funcionamento, aprofundou o descompasso, promovido anteriormente pela globalização, em relação à noção tradicional de soberania. Essa incompatibilidade dificulta o controle da esfera digital por meio de uma legislação própria. Diante deste cenário, observou-se a necessidade de transformação do exercício da soberania, para que ela se tornasse adequada ao modo como este novo ambiente funciona, motivando a sua reformulação por parte de alguns estudiosos como Ávila, Gatto, Franzese e Lessig. Mesmo reformulado, no entanto, esses novos modelos de exercício de soberania ainda não são suficientes para permitir a regulação completa do ciberespaço. Dessa forma, é objetivo deste trabalho, a partir de análise e crítica do acervo bibliográfico levantado, mostrar o motivo da insuficiência dos novos modelos de exercício da soberania quando se considera o modo como o ciberespaço funciona. Ao final, sugere-se que a proposta de Lessig pode ser utilizada como paliativo para mitigar a insegurança jurídica no ciberespaço.

Palavras-chave: Ciberespaço. Soberania. Direito internacional. Regulação internacional. Governança global.

\section{CHALLENGES OF THE EXERCISE OF SOVEREIGNTY IN CYBERSPACE}

\section{ABSTRACT}

Cyberspace, with its way of functioning, has deepened the mismatch previously fostered by globalization in relation to the traditional notion of sovereignty. This incompatibility makes it difficult to control the digital sphere through its own legislation. Given this scenario, it was observed the need to transform the exercise of sovereignty, so that it became appropriate to the way this new environment works, motivating its reformulation by some scholars like Ávila, Gatto, Franzese and Lessig. However, even reformulated, these new models of exercise of sovereignty are still not enough to allow the complete regulation of cyberspace. Thus, the purpose of this paper, based on analysis and reviews of the literacture collection chosen, is to show the reason for the insufficiency of the new models of exercise of sovereignty when considering the way cyberspace works. In the end, it is suggested that Lessig's proposal can be used as a palliative to mitigate legal uncertainty in cyberspace.

Keywords: Cyberspace. Sovereignty. International law. International regulation. Global governance.

\section{SUMÁRIO}

1 Introdução. 2 Evolução histórica do conceito de soberania e sua concepção tradicional. 30 ciberespaço e a crise da soberania. 4 Ciberespaço e a soberania indispensável. 4.1 Crítica aos novos modelos de exercício da soberania. 4.2 A soberania possível no ciberespaço. 5 Conclusão. 6 Referências. 


\section{INTRODUÇÃO}

A soberania surge das necessidades impostas pelo advento do Estado Moderno. Criação humana e, portanto, fruto de processos históricos, os contornos da soberania foram constantemente colocados em xeque, forçando adequações aos novos contextos que surgiram. Sua última transformação mais significativa decorreu da globalização, que deu início à atual crise de soberania no mundo, uma vez que comoveu elementos sensíveis de seu conceito, como território e população.

Apesar desses desafios impostos ao exercício da soberania, o ciberespaço necessita dela para existir e funcionar. Por esse motivo, novos modelos de exercício de soberania foram propostos para tentar se adequar à realidade digital. Autores como Ávila (2014), Gatto (2008) e Franzese (2009) propuseram a ideia de uma soberania compartilhada, alienável e divisível, exercida por organizações internacionais que seriam responsáveis pela regulação do ciberespaço como alternativa ao modelo de soberania estatal.

Esses novos modelos, contudo, não se sustentam em suas bases teóricas e práticas. A realidade mostra que desafios já existentes no modelo tradicional de exercício da soberania persistem. Em primeiro lugar, porque os novos modelos pressupõem um voluntarismo por parte dos Estados, muitos dos quais não podem ser efetivamente coagidos a cumprirem as determinações de organizações internacionais. Isso pôde ser visto, por exemplo, na invasão do Iraque, sem autorização da ONU, por parte dos Estados Unidos, em 2003. Esse comportamento revela a falta de coercibilidade das entidades internacionais, que não conseguem impor suas decisões justamente por não possuírem soberania, uma vez que esta ainda é elemento exclusivo do Estado, não podendo ser transferida nem dividida, exemplo que contrapõe os preceitos das novas formulações de soberania.

Em segundo lugar, para que um organismo internacional possa regular o ciberespaço é necessário que haja um consenso entre as nações, o que até agora se apresentou inviável. Eventos como o NETmundial de 2014 mostram que existem divergências significativas sobre pontos que devem orientar a governança on-line, como a vigilância em massa, a neutralidade e a privacidade.

Diante desta realidade, buscou-se um modelo alternativo de exercício da soberania no ciberespaço que partisse do reconhecimento da inevitabilidade da soberania estatal. Um modelo com essas características foi proposto por Lawrence Lessig (2006), para quem a regulação do ciberespaço deve ser feita com base na nacionalidade do usuário. Independentemente de sua localização geográfica no acesso ao mundo on-line, o indivíduo estaria sujeito às normas de seu país, garantidas pela soberania estatal, que seriam impostas e respeitadas pelos demais países.

Uma investigação mais cuidadosa, porém, torna evidente que a proposta de Lessig (2006) sofre dos mesmos problemas das que foram citadas anteriormente. A obediência às normas internacionais por parte dos Estados se basearia na vontade e não na imposição a partir da coercibilidade oferecida pelo poder soberano. Ademais, Estados poderiam considerar a aplicação de regras não produzidas por eles como uma afronta a sua soberania. Além disso, o conteúdo das normas de cada país também pode gerar divergências entre as nações, dando azo a sua não aplicação em domínio estrangeiro.

Com base na análise das ideias supraindicadas, o presente trabalho busca mostrar que os desafios para uma governança global do ciberespaço persistem. Apesar disso, acredita-se que a proposta de Lessig (2006) pode servir, ainda que de forma precária, para mitigar a imprevisibilidade e a insegurança jurídica decorrentes da frágil governança do ciberespaço, na medida em que permite acordos multilaterais e consensos parciais, para proporcionar regulações provisórias e em pequena escala entre algumas nações.

Para desenvolver a temática proposta, as pesquisas feitas para a confecção deste artigo foram com base em dados secundários provenientes da bibliografia apresentada nas referências. Além disso, este trabalho, de natureza teórica, utiliza dos tipos metodológicos históricos, ao fazer um retrospecto da evolução do conceito de soberania; interpretativo, ao destrinchar o conflito entre globalização, ciberespaço e as noções tradicional e as atuais de soberania trazidas por Ávila (2014), Gatto (2008) e Franzese (2009); e, por fim, propositivo, ao mostrar que as novas concepções de soberania ainda não são suficientes para a regulação do mundo on-line de forma satisfatória. 
Todo o material produzido está organizado em quatro tópicos, sendo primeiro esta Introdução. No segundo tópico será construída uma linha do tempo a respeito do desenvolvimento da noção de soberania até a sua concepção tradicional. O terceiro tópico abordará a crise da definição tradicional de soberania trazida pela globalização e aprofundada pelo advento do ambiente digital. Por sua vez, o quatro tópico abordará criticamente os modelos de exercício da soberania propostos por Ávila (2014), Gatto (2008) e Franzese (2009), explicando os motivos pelos quais esses novos modelos não são suficientes para garantir uma governança eficaz do ciberespaço. Por fim, ainda no tópico quatro, será abordada criticamente uma possível proposta paliativa para que o mundo digital possa ser regulado até o desenvolvimento de um modelo adequado de soberania para este ambiente. Finalmente, na conclusão, será apresentada uma síntese dos apontamentos feitos ao longo do artigo, de modo que se deduza a impossibilidade do exercício da soberania no ciberespaço a partir da definição de poder soberano que se tem atualmente.

\section{EVOLUÇÃO HISTÓRICA DO CONCEITO DE SOBERANIA E SUA CONCEPÇÃO TRADICIONAL}

O conceito de soberania tornou-se objeto de investigação e crítica a partir da Idade Moderna (14531789), tendo como um de seus primeiros pensadores o francês Jean Bodin (1530-1596). Em sua obra Les Six Livres de la République (1576), a soberania é definida como "um poder absoluto e perpétuo" (BODIN apud DALLARI, 2013, p. 83). Absoluto, por nenhum outro poder se sobrepor a ele, exceto o poder divino; perpétuo, por não ter prazo de validade para o seu exercício.

Bodin apenas esboça uma ideia que somente ganhará forma em 1648, com a Paz de Westfália, tratado que, além de colocar fim na Guerra dos Trinta Anos, ${ }^{1}$ foi responsável pela formatação de um sistema internacional de Estados baseado no reconhecimento de sua soberania no âmbito mundial de acordo com a força de cada ente estatal. Nesse contexto, a soberania era entendida como o poder de império de um determinado Estado sobre o seu território, que deveria ser respeitado pelos demais. A partir dessa concepção de soberania, formou-se um complexo internacional em que os Estados eram vistos de modo igual e independente (JO; SILVA SOBRINHO, 2004, p. 13).

A concepção de soberania trazida pela Paz de Westfália permaneceu praticamente incólume até 1815, com o Congresso de Viena. ${ }^{2}$ Influenciado pela Revolução Francesa (1789), o Congresso de Viena adotou a concepção de soberania baseada nas ideias de liberdade e autodeterminação dos povos, inspiradas em John Locke (1824), e vontade geral do povo, de matriz rousseauniana (ROUSSEAU, 2010).

Essa nova concepção, no entanto, aplicava-se apenas aos países europeus, que não viam as localidades fora de seu continente como detentores dessa forma de soberania. Isso porque, apesar de incluir o elemento vontade geral do povo, que se referia especialmente à relação legítima de poder entre súditos e soberano baseada na ideia de pacto social, a concepção de soberania ainda estava "fundamentalmente baseada na força de defesa", servindo "praticamente como o único critério utilizado para a classificação de um país como soberano" (JO; SILVA SOBRINHO, 2004, p. 15). Se, internamente, a soberania pressupunha a vontade geral do povo, no aspecto externo, isto é, na relação com outras entidades de poder no âmbito internacional, ela ainda estava demasiadamente ligada à ideia de poder império. ${ }^{3}$

Em decorrência da Primeira Guerra Mundial (1914-1918), a concepção de soberania sofre uma nova modificação, "indo do antigo sistema de Vestfália, baseado na força e em um conceito político de soberania, para um inteiramente novo sistema legal, baseado na sistematização normativa e em um conceito jurídico de soberania" (JO; SILVA SOBRINHO, 2004, p. 16). Assim,

\footnotetext{
Conflito inicialmente de cunho religioso entre as monarquias da Europa, mas que, posteriormente, envolveu disputas por poder e território. Ocorreu entre os anos de 1618 e 1648.

2 "encontro diplomático de importância fundamental para redesenhar o mapa político europeu na era pós-napoleônica" (VAINFAS et al., 2014, p. 296).

3 Jo e Silva Sobrinho afirmam (2004, p. 15) que essa concepção foi utilizada como tentativa de legitimação da exploração econômica de colônias da África e da Ásia no século 19. Na medida em que não conseguiam afirmar e manter o poder de império sobre o seu território, as colônias não eram soberanas quando confrontadas pelas potências colonizadoras europeias.
} 
em termos puramente políticos, a soberania expressava a plena eficácia do poder, sendo conceituada como poder incontrastável de querer coercitivamente e de fixar as competências [...] verifica-se que o poder soberano não se preocupa em ser legítimo ou jurídico, importando apenas que seja absoluto, não admitindo confrontações, e que tenha meios para impor suas determinações. [...] Uma concepção puramente jurídica leva ao conceito de soberania como o poder de decidir em última instância sobre a atributividade das normas, vale dizer, a eficácia do direito [...] tem-se como soberano o poder que decide qual regra jurídica aplicável em cada caso [...] (DALLARI, 2013, p. 83).

Essa mudança aparece no Pacto da Sociedade das Nações de 1919 que, além de ser um acordo de paz entre os países vencedores do conflito, teve como principal preocupação estabelecer como ponto importante da soberania "o aspecto da não-intervenção em assuntos domésticos" (JO; SILVA SOBRINHO, 2004, p. 18). Assim, a autoridade estatal tinha o poder para tratar de assuntos internos a seu território sem interferências externas.

A explosão da Segunda Guerra Mundial (1939-1945), por sua vez, contribuiu para a extinção do Pacto da Sociedade das Nações de 1919, abrindo espaço para que, em 1945, surgisse a Organização das Nações Unidas (ONU). Em sua carta instituidora, além de reafirmar o princípio da não intervenção em assuntos que pertencem à esfera estatal interna, a ONU também reconhece a igualdade entre as nações no que diz respeito a sua soberania. Preceitos que são abarcados pelo segundo artigo do documento: "todos os membros deverão evitar em suas relações internacionais a ameaça ou o uso da força contra a integridade territorial ou a dependência política de qualquer Estado [...]" (ONU, 1945, p. 6) e ainda "a Organização é baseada no princípio da igualdade soberana de todos os seus membros" (ONU, 1945, p. 6). Assim, essa concepção de soberania propõe, portanto, que todos os países devem ser respeitados e vistos com igual potencial de exercer o seu poder soberano internamente sem influências de agentes externos, independentemente do seu poderio bélico e de sua influência no cenário internacional.

A evolução das concepções de soberania apresentada supra permite elencar alguns aspectos essenciais do que se pode considerar o conceito de soberania. De acordo com Jo e Silva Sobrinho (2004, p. 8), o conceito de soberania é geralmente composto por "quatro elementos: um território, uma população, um governo que exerça um controle efetivo sobre esse território e essa população e, mais importante, o reconhecimento (como Estado) pelos outros Estados-Nações constituintes da sociedade internacional."Krasner (2001, p. 6), por sua vez, propõe quatro perspectivas distintas para compreensão do conceito de soberania. Para ele, existe a soberania doméstica, que diz respeito à organização e ao controle efetivo de uma autoridade pública dentro de um Estado; a soberania interdependente, isto é, o controle das fronteiras por parte das autoridades públicas; a soberania internacional legal, caracterizada pelo reconhecimento recíproco da soberania dos Estados e, por fim, a soberania de Westfália, que estabelece a exclusão de atores externos da soberania doméstica.

É importante acrescentar também as características da soberania trazidas por Dallari (2013). Segundo o autor, a soberania é

una, indivisível, inalienável e imprescritível. Ela é una porque não se admite num mesmo Estado a convivência de duas soberanias. [...]. É indivisível porque, além das razões que impõem sua unidade, ela se aplica à universalidade dos fatos ocorridos do Estado, sendo inadmissível, por isso mesmo, a existência de várias partes separadas da mesma soberania. [...]. A soberania é inalienável, pois aquele que a detém desaparece quando fica sem ela, seja o povo, a nação, ou Estado. Finalmente, é imprescritivel porque jamais seria verdadeiramente superior se tivesse prazo de duração. Todo poder soberano aspira a existir permanentemente e só desaparece quando forçado por uma vontade superior (DALLARI, 2013, p. 87).

Dallari (2013) ainda afirma que a soberania é "uma característica fundamental do Estado" (DALLARI, 2013, p. 80), e "com relação aos demais Estados a afirmação de soberania tem a significação de independência, admitindo que haja outros poderes iguais, nenhum, porém, que lhe seja superior" (DALLARI, 2013, p. 89). Além disso,

o que distingue o Estado das demais pessoas jurídicas de direito público é a circunstância de que só ele tem soberania. Esta, que do ponto de vista interno do Estado é uma afirmação de poder superior a todos os demais, sob o ângulo externo é uma afirmação de independência, significando a inexistência de uma ordem jurídica dotada de maior grau de eficácia (DALLARI, 2013, p. 258). 
Diante das noções de soberania apresentadas, é possível sintetizá-la, no seu sentido tradicional, como poder coercitivo, de exercício exclusivo, permanente e intrínseco ao Estado, de impor um determinado ordenamento jurídico em certo território que contém uma população. Esse poder existe de forma única, não podendo ser executado de modo fracionado, e o Estado não pode transferi-lo a outrem, uma vez que inexiste em sua ausência. Além disso, esse poderio de imposição interno é reconhecido e respeitado internacionalmente, não existindo nenhum poder superior que se sobreponha à soberania estatal.

\section{O CIBERESPAÇO E A CRISE DA SOBERANIA}

Como foi mostrado no capítulo anterior, a soberania sofreu, ao longo do tempo, diversas mudanças em sua definição. Essas constantes alterações revelam que "o conceito de soberania evolui conforme as necessidades da sociedade internacional" (JO; SILVA SOBRINHO, 2004, p. 9). Sua mais recente modificação foi com o desenvolvimento da globalização, que não somente força uma mudança no entendimento e aplicação do poder soberano, mas também causa a sua atual crise.

A globalização é um processo que "rompe as fronteiras territoriais por onde a informação é transmitida pelo globo, e indivíduos podem participar de forma simultânea, independentemente de sua localização geográfica" (ANG; PANG, 2012, p. 117, tradução nossa). ${ }^{4}$ Essa "abertura imposta pela globalização enfraqueceu o poder do Estado-Nação em decidir soberanamente os rumos político-econômicos que irá adotar" (NOCE, 2018, p. 42).

Ao enfraquecer os limites estatais e possibilitar o contato entre sujeitos de nacionalidades distintas, a globalização dificulta o exercício da soberania tradicional, uma vez que o território, elemento constituinte da noção de soberania, tem a sua delimitação prejudicada. A população, por sua vez, outro componente importante, amplia-se e passa a abarcar pessoas de origem variada, o que dificulta a aplicação do direito nacional em relação a uma comunidade que se torna multinacional.

Dessa forma, a globalização coloca o entendimento e o exercício da soberania em crise, pois a sua forma tradicional, apresentada no tópico anterior, não se adéqua a essa nova realidade. Essa crise aprofunda-se com o surgimento do ciberespaço, que possibilita "a globalização de informações, que com o advento da internet [...] a comunicação se tornou consideravelmente mais facilitada e as distâncias para tanto reduzidas" (NOCE, 2018, p. 114).

O ciberespaço, de acordo com o Department of Defense (DOD), no Dictionary of Military and Associated Terms (2017, p. 58, tradução nossa), consiste em "um domínio global dentro do ambiente da informação, incluindo a internet, os canais de telecomunicações, os sistemas de computadores e a integração de processadores e controladores". ${ }^{5} \mathrm{~A}$ forma como esse universo se configura também torna incompatível o exercício da soberania em seu modelo clássico e, consequentemente, dificulta uma possível regulação internacional a respeito.

Isso acontece porque, no ciberespaço, não há limites físicos bem-delineados; ele "é um domínio público global, ou seja, um espaço sem fronteiras que a todos afeta" (GATTO, 2008, p. 6). Por ter abrangência mundial, a sua população de usuários é composta por uma comunidade internacional que, como tal, abarca múltiplas nacionalidades, o que impede que uma única entidade estatal possa controlá-la. Além disso, a falta de um organismo uno e próprio, que tenha competência para regular esta realidade, faz com que os Estados tentem controlar esse universo de acordo com seus regimentos internos, impossibilitando soluções satisfatórias para os conflitos que se formam. Isso acontece, pois as legislações nacionais são baseadas em um modelo tradicional de exercício da soberania que não se aplica ao ambiente digital, pois o "rápido crescimento do ciberespaço ultrapassou a habilidade individual das nações e da comunidade internacional como um todo em entendê-lo e

\footnotetext{
4 "breaking down of geographical or territorial boundaries, where information is transmitted across the globe, and individuals may participate in the same event at the same time, regardless of theis geographical locations [...]".

5 "A global domain within the information environment consisting of the interdependent network of information technology infrastructures and resident data, including the Internet, telecommunications networks, computer systems, and embedded processors and controllers."
} 


\section{Direito自

controlá-lo" (FRANZESE, 2009, p. 6, tradução nossa). ${ }^{6}$ Dessa forma, o que se tem é uma tentativa precária por parte das nações em tentarem exercer sua soberania em uma realidade que não permite o seu exercício nos moldes tradicionais.

Essa tentativa pode ser vista tanto no conflito provocado pela imposição de legislações nacionais a assuntos transnacionais, pois o fato de não haver "limites fronteiriços físicos [...] permite a coexistência de ordenamentos jurídicos distintos, incidentes sobre um mesmo fato" (GATTO, 2008, p. 6), quanto no aproveitamento do ciberespaço por parte dos governos para interferir na soberania de outras nações. Wu e Goldsmith (2006) retratam, a partir de exemplo, o primeiro aspecto abordado, enquanto a interferência russa nas eleições norte-americanas de 2016 reflete o segundo ponto trazido.

Wu e Goldsmith iniciam a sua obra "Who controls the internet? illusions of a bordeless world" (2006) abordando o conflito jurídico entre a empresa Yahoo, sediada na Califórnia, EUA, e a França. Nesse caso, ocorrido em 2000, a nação francesa pedia à empresa americana que proibisse a venda on-line de artigos nazistas, em sua página americana, para usuários franceses, uma vez que esse comércio desrespeitava uma lei francesa que proibia essa conduta. O Yahoo, em resposta, alegou que não adotaria essa medida, pois ela contrariava um dos princípios constitucionais dos Estados Unidos: a liberdade de expressão. ${ }^{7}$ Além disso, segundo a empresa, a França não teria competência para julgar esse caso.

O Estado francês, entretanto, defendia a sua competência para resolver tal tema, determinando judicialmente a proibição da venda dos artigos nazistas pelo Yahoo para os internautas franceses. Os artigos, porém, continuaram a ser vendidos no portal on-line, pois a Califórnia, Estado-sede do Yahoo, não reconhecia a decisão francesa, uma vez que esta contrariava a soberania norte-americana e seus princípios constitucionais. Apesar disso, em 2001, conforme aponta Wu e Goldsmith (2006), o Yahoo removeu toda forma de conteúdo racista e nazista, afirmando que tal atitude foi motivada por reclamações de usuários e não pelo que foi determinado pela corte francesa.

Em 2016, por sua vez, tem-se a interferência russa no processo eleitoral dos Estados Unidos, que buscava, influenciando a soberania norte-americana, satisfazer os interesses de sua própria soberania, como o fim das sanções entre as duas nações. A eleição contava com dois candidatos principais, Donald Trump, do Partido Republicano, e Hillary Clinton, do Partido Democrata, e o governo russo atuou em prol da candidatura do primeiro, pois via neste a possibilidade de atingir os seus objetivos. Para isso, a nação russa "roubou e-mails dos Democratas, atacou a lista e as máquinas de votos e influenciou as redes sociais"8 (McCARTHY, 2017, tradução nossa). Essa empreitada foi possível a partir de "trolls e robôs automatizados que não só promoveram explicitamente mensagens pró-Donald Trump, mas também usaram a mídia social para semear divisões sociais na América incentivando a discordância em torno de temas polêmicos como a imigração e a islamofobia" ${ }^{\prime \prime}$ (McCARTHY, 2017, tradução nossa).

Esses eventos são ilustrativos da crise de soberania relacionada ao ciberespaço. A abrangência mundial e a possibilidade de se conectar agentes dos mais diversos lugares e ocupações, colocam em xeque o exercício e a imposição da soberania em seu formato tradicional e, consequentemente, a competência dos ordenamentos jurídicos internos para resolver questões que são transnacionais. Com isso, o ciberespaço "produz uma espécie de conflito que nunca aconteceu antes: um conflito que surge com indivíduos de diferentes jurisdições vivendo juntos em um [mesmo] espaço, enquanto vivem em diferentes jurisdições" (LESSIG, 2006, p. 300, tradução nossa) $)^{10}$ no mundo off-line.

\footnotetext{
"the rapid growth of cyberspace has outpaced the ability of nations individually, and the international community as whole, to understand and control it."

7 Esse princípio está consusbstanciado na primeira emenda da Constituição norte-americana, que dispõe o seguinte: “Congress shall make no law respecting an establishment of religion, or prohibiting the free exercise thereof; or abridging the freedom of speech, or of the press; or the right of the people peaceably to assemble, and to petition the Government for a redress of grievances" (ESTADOS UNIDOS DA AMÉRICA, 1791).

8 "stealing emails from Democrats, attacking voter registration lists and voting machines and running a social media shell game."

9 "trolls and automated bots not only promoted explicitly pro-Donald Trump messaging, but also used social media to sow social divisions in America by stoking disagreement and division around a plethora of controversial topics such as immigration and Islamophobia."

10 "Will produce a kind of conflict that has never happened before: a conflict arising from individuals from different jurisdictions living together in one space while living in these different jurisdictions."
} 
Esses embates legais, motivados pelo conflito entre as legislações nacionais e, também, pela ausência de uma legislação própria para o ciberespaço, impedem uma solução satisfatória e eficaz para as relações jurídicas formadas nesse domínio, conforme mostrado nos exemplos supranarrados. Conflitos deste tipo podem gerar, em larga escala, insegurança jurídica para todos os usuários do mundo virtual, além de enfraquecer o poder dos Estados, que atuam de forma precária ante o advento do mundo digital.

\section{CIBERESPAÇO E A SOBERANIA INDISPENSÁVEL}

No tópico anterior foram mostradas as dificuldades de a soberania, em seu modelo tradicional, prevalecer no ciberespaço. A possibilidade de regulação do ciberespaço é, contudo, em certo sentido, dependente de elementos essenciais a esse modelo tradicional.

Em primeiro lugar, porque o meio digital demanda uma entidade que o controle, possibilitando, assim, a sua existência e o seu funcionamento harmônico (FRANZESE, 2009, p. 12). Segundo o autor, o ciberespaço demanda, portanto, a existência de um soberano para controlá-lo (FRANZESE, 2009, p. 12). Por outro lado, complementa Franzese (2009, p. 12) que o mundo on-line também exige uma estrutura física, que está baseada em territórios de Estados, o que o vincula, em certa medida, à soberania estatal. Dessa forma, a regulação do ciberespaço não pode ser pensada sem se ter em conta elementos essenciais do modelo tradicional de soberania, apesar dos desafios implicados nessa tarefa, conforme abordado anteriormente.

A partir dessa constatação, alguns autores propuseram novos modelos de soberania que, supostamente, permitiriam o seu exercício no ciberespaço. Ávila (2014) propõe que o "Estado pode abrir mão de sua soberania e, livremente, exercê-la de maneira compartilhada [...]" (ÁVILA, 2014, p. 42). Assim, a "soberania se fragmenta, se desconecta parcialmente do Estado, se liga a regimes, organizações supranacionais [...]" (p. 63). O Estado, nesse contexto, continuaria a existir, mas desempenharia uma nova função, a

de intermediador, que articularia elementos de supra e subnacionalidade, isto é, o Estado negociaria com atores subnacionais e supranacionais, regulando suas relações. Ele seria parte de um mecanismo mais amplo de governabilidade e de compartilhamento de determinados aspectos de seu poder (ÁVILA, 2014, p. 54).

Dessa maneira, sintetizando o ponto de vista suprarreferido, a soberania do Estado seria dividida com os demais Estados em uma única organização que regularia o ciberespaço. Ao mesmo tempo, essa entidade condensaria todas as soberanias a ela transferidas, o que permitiria o controle do ciberespaço de forma concentrada, exercida por um único agente, acima dos Estados. $O$ ente estatal, nessa realidade, seria apenas o elo entre os assuntos internos e externos à nação.

Gatto (2008), por sua vez, corrobora a visão de Ávila ao propor o seu modo de exercício da soberania no ciberespaço. De acordo com a autora, o mundo on-line "é um espaço sem fronteiras, sujeito a múltiplas soberanias, sem a prevalência de uma só" (GATTO, 2008, p. 135). Para que a síntese dessas soberanias seja possível, a "governança da internet demanda que os países estabeleçam um consenso [...]" (p. 6), tornando-se "imprescindível [...] admitir um organismo internacional para a Governança Global da Internet [...]" (p. 135).

Dessa forma, resumindo o posicionamento da autora, pode-se afirmar que o exercício da soberania no ciberespaço se dará por meio de uma entidade internacional. Esta conterá todas as soberanias estatais de forma única, regulando o meio digital com base em um consenso entre as nações que a constituem, exercendo uma governança global ${ }^{11}$ do mundo on-line.

Franzese (2009, p. 28) reforça a concepção de Gatto no que diz respeito à necessidade de consenso para que a soberania possa ser exercida no ciberespaço. Para isso, o autor estabelece algumas condições, como: a necessidade de um regime internacional, a avaliação por parte dos Estados de seus interesses no ciberespaço, a análise da forma como se exercerá a soberania estatal pelos mesmos entes estatais, a identificação dos agentes que participam do mundo on-line e, por fim, a capacidade estatal em praticar a sua soberania e responder àqueles que violam o seu poder soberano (p. 32).

\footnotetext{
11 "A governança global reside no processo de construção das instituições [...] e dos regimes internacionais para a regulação dos desafios contemporâneos" (BARROS-PLATIAU, 2001, p. 6).
} 
Desse modo, recapitulando os pontos de vista apresentados, pode-se concluir que o ciberespaço necessita da prática soberana para funcionar de forma eficaz. Como mostrado, no entanto, deve-se aplicar um novo modelo de exercício de soberania para esse domínio. Para isso, deve-se criar uma entidade internacional que condense todas as soberanias estatais, que deixam de pertencer exclusivamente ao Estado e se concentram em organismos externos. Esses órgãos serão competentes para regular o ciberespaço a partir de um consenso de princípios entre seus membros estatais, que possibilitará a formulação de normas próprias para esse ambiente.

\subsection{Crítica aos novos modelos de exercício da soberania}

No tópico anterior, a partir da constatação de que o ambiente digital necessita da prática soberana para que exista e funcione de forma adequada, foram abordados novos modelos de soberania que surgiram no intuito de se adequar ao ciberespaço. Mesmo esses novos modelos, entretanto, são insuficientes para que a soberania seja exercida de forma satisfatória no mundo on-line.

No modelo de Ávila, o Estado transfere a sua soberania para órgãos internacionais, compartilhando-a com estes e com os demais entes estatais que formam essas entidades (ÁVILA, 2014, p. 42). Essa realidade, para o autor, reflete em uma soberania "alienável e divisível" (p. 58), o que permite que a soberania se desprenda de forma parcial do Estado (p. 63).

O problema desse modelo é o seu embate com traços elementares da soberania, como o fato de ela ser indivisível e inalienável. Segundo Dallari (2013), a soberania é indivisível, pois "se aplica à universalidade dos fatos ocorridos do Estado, sendo inadmissível, por isso mesmo, a existência de várias partes separadas da mesma soberania" (p. 87). Dessa forma, não é possível que o Estado tenha somente uma parcela de sua soberania enquanto uma entidade internacional contenha a outra, uma vez que é necessidade do Estado a totalidade do poder soberano para se impor em relação aos eventos que são de sua responsabilidade. Além disso, a soberania "é inalienável, pois aquele que a detém desaparece quando fica sem ela, seja o povo, a nação ou Estado" (DALLARI, 2013, p. 87). Assim, transferir uma parte da soberania estatal para uma organização internacional é comprometer a existência do Estado e do seu povo, que necessitam dela em sua totalidade para se manterem.

Essas características impedem que organizações internacionais tenham soberania e, consequentemente, coercibilidade para impor suas decisões. Isto acontece porque, ainda segundo Dallari, o Estado não admite a existência de um poder que seja superior ao seu (2013, p. 89). Dessa forma,

o que distingue o Estado das demais pessoas jurídicas de direito público é a circunstância de que só ele tem soberania. Esta [...] sob o ângulo externo é uma afirmação de independência, significando a inexistência de uma ordem jurídica dotada de maior grau de eficácia (p. 258).

Um exemplo desse poder reduzido das organizações internacionais, justamente, por não serem dotadas de soberania, é a invasão do Iraque em 2003 pelos Estados Unidos sem autorização da ONU. Os norte-americanos justificaram a sua ação com "argumentos de legítima defesa preventiva, ou mesmo em nome da democracia e dos direitos humanos" (PLATIAU; VIEIRA, 2006, p. 190). Sua atitude, no entanto, contrariava resoluções da ONU que impediam a invasão. Mesmo assim, os Estados Unidos procederam em sua ação, não sendo um impedimento as determinações da organização internacional da qual é membro.

A conduta norte-americana contrária às determinações da ONU revela que, por parte das entidades internacionais, "não há poder coercitivo para impor legalmente uma determinada conduta aos Estados, fazendo com que a adesão dos mesmos às normas internacionais seja de forma voluntária" (RUDZIT, 2005, p. 63). Aderir de forma voluntária abre aos Estados a possibilidade de obedecer ou não as ordens destas organizações, uma vez que a decisão de participar destes órgãos vem de uma escolha e não de uma imposição dotada de coercibilidade como acontece com a soberania.

Aplicando o mesmo raciocínio exposto, pode-se afirmar que as entidades internacionais que viessem a regular o ciberespaço sofreriam com o mesmo problema. Os Estados participariam de forma voluntária, podendo, com isso, acatar ou não suas decisões e obedecer ou não as regras criadas pela entidade reguladora do mundo on-line. Isso aconteceria, justamente, pelo fato de que os Estados têm soberania, enquanto as orga- 
nizações internacionais não a possuem e, como já mencionado anteriormente, não existe poder superior que se sobreponha à soberania estatal. Por isso, entidades internacionais não apresentam capacidade de impor as suas determinações com a mesma imperatividade que o poder soberano estatal permite.

Outra questão problemática, no que diz respeito à regulação internacional do ciberespaço, é a formação de um consenso para orientar o conteúdo das normas que seriam aplicadas a essa realidade. Segundo Gatto (2008), "a governança da Internet demanda que os países estabeleçam um consenso [...]". No entanto, a realidade está muito distante desse consenso. Veja-se, por exemplo, o evento NETmundial ${ }^{12}$ de 2014 realizado no Brasil. $\mathrm{O}$ acontecimento tinha como objetivo "a realização de um marco, com definições consistentes para os princípios de governança da Internet e o roteiro para o desenvolvimento futuro da governança da Internet" (NETMUNDIAL, 2014). Não obstante,

O debate sobre a governança da internet, a partir do evento NETmundial, foi um importante exemplo prático para se demonstrar que não há convergências em torno de determinados assuntos de modo a se constituir um regime de caráter mais amplo. Temáticas como vigilância em massa, neutralidade da rede, privacidade, papéis e responsabilidades entre atores, por exemplo, evidenciaram o quanto se precisa avançar em termos de discussão para que se constitua um regime global para a questão (ÁVILA, 2014, p. 267).

Um exemplo mais específico da dificuldade de criar um consenso pode ser visto na questão da vigilância em massa. No ano de 2013, os Estados Unidos foram acusados de espionarem seus cidadãos e outros governos. Sobre os norte-americanos, a "Agência Nacional de Segurança (NSA) [...] acessava fotos, e-mails e videoconferências de quem usava os serviços de empresas como Google, Skype e Facebook" (PEDROSA; MATSUKI, 2013). Em relação a outras nações, a ex-presidenta brasileira Dilma Rousseff teve seus telefonemas, mensagens e e-mails interceptados pelo governo norte-americano (O ESCÂNDALO..., 2013).

A conduta dos Estados Unidos motivou a União Europeia a adotar uma postura refratária à vigilância em massa. No dia 25 de maio de 2018 entrou em vigência para o bloco europeu uma lei, conhecida como Regulamento Geral de Proteção de Dados, que visa à proteção de dados pessoais dos cidadãos que moram no bloco e determina a conduta de empresas que atuam no continente europeu no que diz respeito à coleta destes dados. (GOMES, 2018).

Outro ponto controvertido é a neutralidade da rede. ${ }^{13}$ O Brasil, em 2014, com a Lei 12.965, criou o Marco Civil da Internet, com o objetivo de estabelecer parâmetros para o uso da rede no país. $\mathrm{O}$ artigo 30, inciso IV, da referida lei, elenca como princípio orientador da disciplina de uso da internet a "preservação e garantia da neutralidade da rede" (BRASIL, 2014). Por outro lado, o mesmo princípio não é mais garantido nos Estados Unidos. O Estado norte-americano, em abril de 2018, decidiu pelo fim da neutralidade da rede (FIM..., 2018), permitindo que as empresas digitais determinem a distribuição de dados aos seus usuários.

Esses dois exemplos apresentados revelam a falta de consenso entre os países sobre pontos que devem nortear a regulação do ciberespaço. As divergências em aspectos básicos do mundo on-line dificultam a possibilidade de criação de normas que possam ser empregadas de forma universal em questões internacionais que nasçam nesse espaço. Para um modelo de exercício de soberania que pressupõe o consenso, essa realidade implica um verdadeiro obstáculo à sua instituição.

Dessa forma, resumindo a crítica apresentada, pode-se afirmar que os modelos propostos por Ávila (2014), Gatto (2008) e Franzese (2009) não são passíveis de aplicação. Apesar de o ciberespaço necessitar da soberania, ela não pode ser exercida da forma que os autores mencionados propõem. O poder soberano permanece indivisível, uma vez que o Estado necessita de sua totalidade para se impor em seu domínio. Além disso, ele é inalienável, pois sua transferência ou divisão comprometem a existência estatal. Assim, somente o ente nacional pode ser detentor da soberania, impedindo a presença de um poder que seja superior.

\footnotetext{
${ }_{12}$ Disponível em: http://netmundial.br/pt/.

13 "A neutralidade da rede é um princípio que está no cerne do funcionamento da internet e diz respeito a uma gestão de tráfego de dados que não faz distinção de pacotes de acordo com seu conteúdo, plataforma ou site de origem, não privilegia determinados tipos de conteúdo, sendo que a rede apenas transporta os pacotes de dados, deixando para o usuário as decisões em relação ao tipo de uso que fará e aos dados que acessará" (SANTOS, 2014).
} 
Com isso, não há a possibilidade de uma entidade internacional apresentar a mesma coercibilidade em suas decisões que a deliberação estatal apresenta, uma vez que não é capaz de possuir soberania. Isso impacta na existência de uma organização internacional para regulação do ciberespaço, pois a obediência ou não a resoluções de entes internacionais se baseia no voluntarismo por parte de seus membros, o que constitui uma fraqueza na imposição de suas ordens. Ademais, mesmo que existisse um órgão internacional para controlar o ciberespaço, haveria ainda uma dificuldade na formulação de normas, uma vez que, como mostrado neste tópico, há um entrave na formação de um consenso sobre pontos essenciais que devem nortear a produção normativa, como a vigilância em massa, a privacidade e a neutralidade em rede.

\subsection{A soberania possível no ciberespaço}

Como mostrado no tópico anterior, apesar de os novos modelos prometerem resolver as dificuldades de exercício da soberania no ciberespaço, eles não conseguem fazê-lo. Primeiro, porque ignoram características essenciais do poder soberano, como a indivisibilidade e a inalienabilidade. Segundo, porque dependem demasiadamente do consenso, cuja obtenção tem se mostrado cada vez mais difícil.

O fracasso desses modelos, porém, não denota a impossibilidade da soberania no ciberespaço, que, inclusive, é necessária. Ele tão somente indica que um modelo de governança adequado ao ciberespaço não pode prescindir da soberania estatal. Nesse sentido, partindo justamente do reconhecimento da inevitabilidade da soberania estatal, Lawrence Lessig (2006) propõe que a regulação do mundo on-line seja feita com base na nacionalidade do usuário.

A maneira como o ciberespaço funciona permite a identificação, dentre outras informações, da nacionalidade de quem acessa o mundo on-line (LESSIG, 2006). A partir disso, seria possível a submissão do usuário à jurisdição de seu Estado de origem, independentemente do local geográfico em que o ambiente digital é acessado. Para que isso fosse possível, haveria uma espécie de convenção, baseada em relações multilaterais entre os Estados, em que cada um definiria "regras que queira aplicar aos seus próprios cidadãos enquanto estes mesmos cidadãos estão em qualquer parte do mundo"14 (LESSIG, 2006, p. 306, tradução nossa). As normas de cada governo estabelecidas nesta convenção seriam de conhecimento público e "disponíveis para qualquer servidor da rede"15 (p. 306, tradução nossa).

Dessa forma, seria uma exigência por parte dos entes estatais aos servidores para que obedecessem aos preceitos que foram definidos na convenção. Assim, tendo como base o exemplo dado por Wu e Goldsmith (2006), e apresentado anteriormente neste trabalho, a respeito do embate entre o Yahoo e a França sobre a venda de material nazista para os franceses, de acordo com o pensamento de Lessig (2006) deveria ser resolvida da seguinte forma: "se você está oferecendo material nazista e um cidadão francês entra em seu site, você deve bloqueá-lo, mas se ele for dos EUA, você poderá atendê-lo"16 (p. 307, tradução nossa). Desse modo, os Estados trabalhariam de forma cooperativa e recíproca ao possibilitar que aqueles que acessam o mundo on-line no seu território sejam regidos pela jurisdição correspondente à sua nacionalidade. Com isso, seriam impostas ao ciberespaço leis locais, garantidas pela soberania estatal (p. 307).

A proposta de Lessig (2006), contudo, não é invulnerável aos problemas já trazidos neste trabalho. Como foi apresentado no caso da invasão do Iraque pelos Estados Unidos, que desobedeceu a resoluções da ONU a respeito, o cumprimento a preceitos não produzidos pelo próprio Estado é, em certo sentido, voluntária. Além disso, os países poderiam ver a imposição de regras alheias dentro de seu território como uma afronta a seu poder soberano, uma vez que existiria outro polo criador de regras capaz de se impor em seu domínio, contrariando outro traço fundamental da soberania: a unicidade, isto é, "não se admite num mesmo Estado a convivência de duas soberanias" (DALLARI, 2013, p. 87).

\footnotetext{
${ }^{14}$ rules that a government wants to apply to its own citizens while those citizens.

15 and available to any server on the network.

${ }^{16}$ if you're offering Nazi material, and a French citizen enters your site, you should block her, but if she is a U.S. citizen, you can serve her.
} 
Ademais, a falta de consenso sobre pontos fundamentais que deveria nortear a regulação do ciberespaço, mostrada previamente, também existiria na suposta convenção, trazida por Lessig (2006), para que os países definissem as normas que deveriam ser aplicadas aos seus nacionais dentro do mundo on-line. Nessa situação, poderia haver divergências entre os Estados sobre o conteúdo destas normas, motivando ou não a sua aplicação em suas jurisdições.

Apesar das inconsistências da proposta de Lessig (2006), sua ideia poderia ser aplicada de forma paliativa até que um modelo adequado de governança para o ciberespaço seja efetivamente estabelecido. $O$ que torna sua proposta preferível às demais trazidas neste trabalho são algumas diferenças que sua sugestão apresenta em relação às outras. Enquanto os modelos criados por Ávila (2014), Gatto (2008) e Franzese (2009) pressupõem um novo conceito de soberania, Lessig (2006) utiliza da soberania estatal que, afora o seu enfraquecimento pela globalização, como mostrado anteriormente, ainda permanece vigente. Com isso, é possível, em certa medida, regular o ciberespaço a partir da nacionalidade do usuário, pois esse aspecto tem como base um dos elementos essenciais da concepção clássica de soberania, isto é, o povo, que se forma, justamente, a partir da noção de nacional.

Além disso, enquanto Ávila (2014), Gatto (2008) e Franzese (2009) recomendam a existência de uma entidade internacional que promova a governança do mundo digital com poder superior aos demais Estados e concentrando suas soberanias, Lessig (2006) apresenta a ideia de uma convenção multilateral realizada pelos próprios Estados que, apesar de impossibilitar a existência de um consenso total, como visto previamente, pode permitir consensos parciais a partir de acordos entre duas ou mais nações ou dentro de blocos e, consequentemente, uma regulação em menor escala, como aconteceu em 2018 na União Europeia por meio do Regulamento Geral de Proteção de Dados, que legisla sobre a conduta das empresas no que diz respeito à coleta de dados pessoais dentro do território europeu.

É nesse contexto que se pode considerar o modelo de Lessig (2006) como paliativo até a criação de um modelo de soberania que permita o seu exercício pleno do ciberespaço e, consequentemente, garanta sua regulação. Isso acontece, pois, apesar de apresentar alguns problemas das propostas anteriores, a sugestão de Lessig, partindo da soberania estatal, permite a resolução parcial das dificuldades encontradas, o que ameniza as complicações trazidas pela insegurança e imprevisibilidade jurídicas do ambiente on-line causadas pela ausência de uma noção suficiente de poder soberano para esse domínio, ainda que não as resolvam de forma completa.

\section{CONCLUSÃO}

A noção tradicional de soberania a considera um poder coercitivo, de exercício exclusivo, permanente e intrínseco ao Estado, que impõe um determinado ordenamento jurídico em certo território que contém uma população. Esse poder existe de forma única, não podendo ser executado de modo fracionado, e o Estado não pode transferi-lo a outrem, uma vez que o próprio Estado deixa de existir na ausência de soberania. Além disso, esse poderio de imposição interno é reconhecido e respeitado internacionalmente, não existindo nenhum poder superior que se sobreponha à soberania estatal.

Esse entendimento entra em crise com o desenvolvimento da globalização, uma vez que, ao permitir o contato entre sujeitos de nacionalidades distintas, ela prejudica a delimitação do território, um dos aspectos elementares da concepção clássica de soberania. Além disso, a população, outro componente importante, amplia-se e passa a abarcar pessoas de origem variada, o que dificulta a aplicação do direito nacional em relação a uma comunidade que se torna multinacional.

A crise trazida pela globalização aprofunda-se com o advento do ciberespaço, que não tem limites físicos bem-delineados. Sua abrangência mundial cria uma comunidade internacional que, abarcando múltiplas nacionalidades, extrapola barreiras geográficas e os ordenamentos jurídicos nacionais, o que impede que uma única entidade estatal possa controlá-la. Além disso, a ausência de um organismo uno e próprio que tenha competência para regular essa realidade, faz com que os Estados, mesmo diante de usuários de nacionalidades diversas, tentem controlar esse universo de acordo com seus regimentos internos, que, se baseando em um conceito tradicional de soberania, impossibilita soluções satisfatórias para os conflitos que se formam nesse ambiente e que demandam outros modos de exercício de poder soberano. 
Diante dessa realidade, vários autores propuseram novas concepções de soberania para que ela se adéque ao mundo on-line. Franzese (2009) ressalta a importância da prática soberana para que o ciberespaço exista e funcione de maneira adequada, e traz a necessidade de consenso entre os atores internacionais para que isso aconteça. Ávila (2014), por sua vez, traz a noção de uma soberania compartilhada, divisível e alienável, que se exerce por meio de uma entidade internacional que possa, assim, regular o ambiente digital. Gatto (2008), além de corroborar com a visão de Ávila, ressalta a necessidade de consenso para que o organismo internacional possa exercer a governança do ciberespaço.

De fato, o ambiente digital precisa de soberania para que possa funcionar protegido pela segurança jurídica. Não há, no entanto, como corroborar os novos modelos de exercício de soberania propostos, uma vez que eles não se sustentam por colocar em xeque aspectos elementares da própria soberania. Além disso, a dificuldade de formação, manutenção e execução de acordos entre as nações sobre pontos que devem nortear a regulação do ciberespaço, torna a solução consensual inviável.

Pelo fato de o Estado ser o único e verdadeiro detentor de soberania, as decisões dos organismos internacionais não são dotadas de coercibilidade e, por isso, são obedecidas ou não, pelos Estados, de forma voluntária. Esta mesma lógica seria aplicada às entidades internacionais de regulação do ciberespaço, que não seriam capazes de impor suas normas aos seus membros que, por apresentarem maior poder, poderiam obedecê-las ou não.

Por outro lado, o consenso entre as nações a respeito de pontos cruciais para a governança do ambiente on-line tem se mostrado difícil de obter. Aspectos como a neutralidade, a vigilância em massa e a privacidade, são alvos de divergências entre os países que se tornaram transparentes em eventos como o NETmundial de 2014. Essas discordâncias dificultam a criação de normas que possam ser empregadas de forma universal em questões transnacionais que surgem nesse espaço.

Diante dos problemas apresentados, outras propostas são desenvolvidas na tentativa de trazer alternativas para o controle do ciberespaço. Uma delas foi criada por Lessig (1006), que sugere a identificação da nacionalidade do usuário do mundo on-line para que se aplique a jurisdição correspondente e não a do espaço geográfico a partir do qual ele acessa o ciberespaço. Isso aconteceria a partir de uma convenção entre os países em que cada um determinaria as regras a serem impostas para os seus nacionais por parte das outras nações.

Mesmo, entretanto, não se preocupando em desenvolver uma nova concepção de soberania para o ambiente on-line, partindo, igualmente, da ideia de soberania centrada no Estado, a ideia de Lessig enfrenta problemas semelhantes aos apontados nas propostas de Franzese, Gatto e Ávila. A obediência de normas alheias às produzidas pelo próprio Estado depende de um voluntarismo, o que permite tanto a aceitação quanto a não aceitação. Além disso, os países poderiam considerar a imposição de normas de outras nações dentro de seu território como uma afronta à sua soberania.

Apesar dos questionamentos a respeito da proposta de Lessig, até a criação de um modelo de soberania que permita o seu exercício pleno do ciberespaço, ela pode servir de paliativo para mitigar problemas de imprevisibilidade e insegurança jurídicas no mundo digital; isso porque o modelo deste autor tem como base a soberania estatal que, apesar de enfraquecida com o advento da globalização, ainda se aplica na realidade atual, o que permite uma regulação provisória a partir da nacionalidade do usuário, tendo como elemento-chave a noção de povo. Além disso, a proposta de Lessig (2006) possibilita acordos multilaterais entre Estados que não precisam, necessariamente, envolver a totalidade das nações, o que pode proporcionar consensos parciais e, consequentemente, uma regulação do mundo digital em pequena escala.

Mesmo com essa medida paliativa, é imprescindível a realização de esforços no intuito de se buscar novas alternativas de controle e regulação de uma realidade que avança a proporções geométricas e que se torna cada vez mais presente no cotidiano e nas relações humanas.

\section{REFERÊNCIAS}

ANG, P. H.; PANG, N. Globalization of the internet, sovereignty or democracy: the trilema of the internet governance forum. Revue Française d'études américaines, Paris, n. 134, p. 114-127, abr. 2012. Available from: https://www.cairn.info/revue-francaise-d-etudes-americaines-2012-4-page-114.htm. Cited: 11 jun. 2018.

ÁVILA, R. O. Regimes internacionais e poder informacional: o caso da Netmundial. 2014. Tese (Programa de Pós-Graduação em Ciência da Informação) - Universidade Federal de Minas Gerais, , 2014. Disponível em: http://www.bibliotecadigital.ufmg.br/ dspace/bitstream/handle/1843/BUBD-9RFJG5/tese_para_impress_o_a_partir_p_g_5.pdf?sequence=1. Acesso em: 3 jan. 2018. 
BARROS-PLATIAU, A. Novos atores, governança global e o direito internacional ambiental. In: COLÓQUIO DO CENTRO DE DIREITO INTERNACIONAL DA UNIVERSIDADE DE PARIS, 10., 2001, França. Disponível em: http://www.egov.ufsc.br/portal/sites/ default/files/anexos/31997-37543-1-PB.pdf. Acesso em: 22 maio 2018.

BRASIL. Lei no 12965 de 23 de abril de 2014. Estabelece princípios, garantias, direitos e deveres para o uso da Internet no Brasil. Diário Oficial da União, Brasília, 23 abr. 2014. Disponível em: http://www.planalto.gov.br/ccivil_03/_ato2011-2014/2014/ lei/l12965.htm. Acesso em: 7 jun. 2018.

DALLARI, D. A. Elementos de teoria geral do Estado. 32. ed. São Paulo: Editora Saraiva. 2013.

DEPARTAMENTO DE DEFESA DOS ESTADOS UNIDOS. DOD Dictionary of Military and Associated Terms. Estados Unidos, 2017.

DWORKIN, G. The Theory and Practice of Autonomy. New York: Cambridge University Press, 1988.

ESTADOS UNIDOS DA AMÉRICA. Constituição (1787). Emenda constitucional n. 1, de 15 de dezembro de 1791. (The Constitution of the United States).

"FIM" da neutralidade da rede começa a valer em abril nos EUA. Portal G1, São Paulo, 22 fev. 2018. Disponível em: https://g1. globo.com/economia/tecnologia/noticia/fim-da-neutralidade-de-rede-comeca-a-valer-em-abril-nos-eua.ghtml. Acesso em: 7 jun. 2018.

FRANZESE, P. W. Sovereignty in cyberspace: can it exist? Air Force Law Review, v. 64, n. 1, p. 1-42, 2009. Available from: https:// www.law.upenn.edu/live/files/3473-franzese-p-sovereignty-in-cyberspace-can-it-exist. Cited: 24 nov. 2017.

GATTO, R. F. O impacto da governança da internet sob o prisma da soberania. 2008. Dissertação (Programa de Pós-Graduação em Direito) - Pontifícia Universidade Católica de São Paulo, ,2008. Disponível em: https://sapientia.pucsp.br/bitstream/handle/8130/1/Raquel\%20Fortes\%20Gatto.pdf. Acesso em: 7 out. 2017.

GOMES, H. Lei da União Europeia que protege dados pessoais entra em vigor e atinge todo o mundo; entenda. Portal G1, São Paulo, 25 maio 2018. Disponível em: https://g1.globo.com/economia/tecnologia/noticia/lei-da-uniao-europeia-que-protege-dados-pessoais-entra-em-vigor-e-atinge-todo-o-mundo-entenda.ghtml. Acesso em: 22 jun. 2018.

JO, H. M.; SILVA SOBRINHO, M. Soberania no direito internacional: evolução ou revolução? Revista de Informação Legis/ativa, Brasília, v. 41, n. 163, p. 7-30, jun./set. 2004. Disponível em: http://www2.senado.leg.br/bdsf/bitstream/handle/id/975/R16301.pdf?sequence=4. Acesso em: 7 out. 2017.

KRASNER, S. D. Problematic Sovereignty: contested rules and political possibilities. New York: Columbia University Press, 2001. LESSIG, L. Code. Nova York: Basic Books, 2006.

LOCKE, J. The Works of John Locke in Nine Volumes. 12th ed. London: Rivington, 1824. V. 4. Available from: http://oll.libertyfund.org/titles/763. Cited: 1ㅇ ago. 2015.

McCARTHY, T. How Russia used social media to divide Americans. The Guardian, Londres, 14 out. 2017. Available from: https:// www.theguardian.com/us-news/2017/oct/14/russia-us-politics-social-media-facebook. Cited: 15 jun. 2018.

NETMUNDIAL. Declaração multissetorial do NETmundial é apresentada. São Paulo, 2014. Disponível em: http://netmundial.br/ pt/2014/05/07/declaracao-multissetorial-do-netmundial-e-apresentada/. Acesso em: 22 jun. 2018.

NOCE, U. A. O (des) interesse público e a intervenção estatal na economia: uma análise sob a ótica da nova racionalidade neoliberal. Belo Horizonte. 2018. Dissertação (Programa de Pós-Graduação em Direito) - Pontifícia Universidade Católica de Minas Gerais, Belo Horizonte, 2018.

O ESCÂNDALO da espionagem dos EUA. O Globo, Rio de Janeiro, 28 set. 2013. Disponível em: https://oglobo.globo.com/mundo/o-escandalo-da-espionagem-dos-eua-10191175. Acesso em: 22 jun. 2018.

ONU. Organização das Nações Unidas. A Carta das Nações Unidas. São Francisco, 1945.

PEDROSA, L.; MATSUKI, E. Entenda o caso Snowden: Petrobrás também é alvo de espionagem. Portal EBC, Brasília, 28 ago. 2013. Disponível em: http://www.ebc.com.br/tecnologia/2013/08/web-vigiada-entenda-as-denuncias-de-edward-snowden. Acesso em: 7 jun. 2018.

PLATIAU, A.; VIEIRA, P. A legalidade da intervenção preventiva e a Carta das Nações Unidas. Revista Brasileira de Política Internacional, Brasília, 49, p. 179-193, 2006. Disponível em: http://www.redalyc.org/html/358/35849110/. Acesso em: 20 jun. 2018. ROUSSEAU, J. O contrato social. Oeiras: Ad astra et ultra, 2010.

RUDZIT, G. ONU, ordem internacional e terrorismo. Revista de Economia e Relações Internacionais, São Paulo, v. 4, n. 7, p. 5768, jul. 2005. Disponível em: http://www.faaptec.edu.br/revista_faap/rel_internacionais/pdf/revista_economia_07.pdf\#page=57. Acesso em: 28 maio 2018.

SANTOS, V. W. O. Governança da internet no Brasil e no mundo: a disputa em torno do conceito de neutralidade da rede. Revista ComCiência, Campinas, n. 158, maio 2014. Disponível em: http://comciencia.scielo.br/scielo.php?script=sci_arttext\&pi$\mathrm{d}=\mathrm{S} 1519-76542014000400009 \&$ Ing=pt\&nrm=isso. Acesso em: 25 jun. 2018.

VAINFAS, R. et al. História: volume único. 2. ed. São Paulo: Saraiva, 2014.

WU, T.; GOLDSMITH, J. Who controls the internet? Illusions of a borderless world. New York: Oxford University Press, 2006. Available from: http://cryptome.org/2013/01/aaron-swartz/Who-Controls-Net.pdf. Cited: 7 out. 2017. 